\title{
EL DERECHO DEL MAR Y LA CONFERENCIA DE CARACAS
}

I

A fines de este mes se iniciaron en Caracas las deliberaciones de la Conferencia mundial sobre Derecho del Mar que, convocada por Naciones Unidas y con la perspectiva de continuar en una segunda reunión en 1975, habrá de completar y revisar los deficientes y discutibles resultados que alcanzaron en esa rama jurídica las Conferencias de Ginebra de 1958 y 1960. Hace falta una divulgación de este tema.

Era indispensable un certamen internacionaı para poner al día las ya caducas instituciones del antiguo Derecho Marítimo, pues el vertiginoso desenvol vimiento que en el presente siglo han alcanzado ciertos fenómenos sociales (tales como la superpoblación humana, la escasez de alimentos, la contaminación atmosférica y marina, el admirable avance de la tecnología y la evolución de las tendencias socio. lógicas bajo el influjo de dos guerras mundiales) determina un profundo impacto en el Derecho $y$ ha dejado rezagados muchos vigentes mecanismos del ordenamiento social.

De ahi que tenga yo como seguro que el fracaso virtual de las dos citas de Ginebra mencionadas arriba obedeció a que en ellas parecía ignorarse la verdadera dimensión de aquellos fenómenos $y$, por timidez o por cautela, se acudió a reformas de sim. ple remiendo o de cariz transaccional, sin dar la debida importancia a algo que debió ser y debe seguir siendo el supremo concepto inspirador de la reforma en la legislación marítima, a saber: la necesidad de crear un derecho NUEVO, acorde con las necesidades de los pueblos del mundo en que hoy vivimos $y$ no vaciado en esquemas fenecidos $e$ inoperantes.

Esta aserción de que la tarea de la actual Con- ferencia está llamada a consistir en una radical inno. vación del Derecho del Mar es una verdad tamaña, cuya comprobación fluye de un simple repaso histó. rico. Valga como ejemplo una ojeada al mundo de los siglos XVIII y XIX, en los cuales proliferaron los intentos de fijar en tres millas la anchura de los mares territoriales. En esos tiempos, las naciones alcanzaban apenas la cincuentena. Buen número de ellas, con la etiqueta de Estados, eran tan sólo pueblos débiles en recursos, en desarrollo, en cultura y en medios de defensa: cuasi-Estados, para decir verdad, en quienes el atributo de la soberanía funcio: naba a menudo como obsecuencia ante el consejo o la demanda de algún "Grande". Otras de esas naciones, en apreciable proporción, vivían sometidas al sistema colonial entonces imperante, ya en tanto que colonias propiamente dichas o bajo el ropaje de un "protectorado", pero en todos los casos desprovistas de la autonomía de Estados. El grupo de las grandes potencias, muy pequeño por cierto, ejercía en realidad no sólo el pilotaje de la política mundial, sino la orientación y patronazgo del Derecho Internacional positivo; funciones éstas que, en veces, asumian forma pfesionante en el campo de las relaciones diplomáticas con estados de menor poderío.

* Nota de Redacción.- Este artículo fue redactado por el autor en junio de 1974 y publicado por partes en el diario El Comercio cuando recién se iniciaba la Tercera Conferencia Mundial sobre Derecho del Mar, celebrado en Caracas, cuya primera reunión ha concluido en agosto de 1974. La revista DERECHO publica el artículo, debido a la importancia del mismo que, en forma clara y sintética, resume la posición de quien siendo Presidente de la República, en 1947 promulgó el Decreto Supremo que estableció la soberania marítima del Perú hasta las 200 millas. Publicamos también en esta sección, un trabajo del Dr. Enrique García Sayán, quien participó en esta iniciativa cuando era Canciller del Gobierno del Dr. Bustamante. 
Así se forjó en aquellos siglos una etapa del Derecho Internacional. Mas esto no era, en verdad, Derecho Internacional genuino: era una tutoria del Derecho en la cual a los Estados-pupilos les faltaba capacidad de acción para participar del libre diálogo jurídico.

De este clima de entraña política, de ausencia de doctrina, de merma de la libertad contractual fue hija la concepción de las tres millas, cuya filosofía no ostentaba más justificación que las exigencias de la defensa militar medidas por el alcance del tiro de cañón. Fue, además, aquella una concepción rudimentaria, miope, sin hondura de análisis: al reconocer a todos los Estados mares territoriales de una anchura invariablemente uniforme de tres millas marítimas, sus autores no pensaron que las costas de cada país ofrecen gran variedad de características $y$ de condiciones geográficas que las diferencian entre si $y$ hacen también diferentes las" posibilidades de aprovechamiento que cada Estado puede asignar a su mar aledaño en función de las necesidades esenciales de sus pobladores y en función también de la mayor o menor amplitud de dimensiones de la fachada marítima de sus costas propias.

La condición de un país que linda en su ribera con un océano abierto a miles de millas de longitud aguas afuera no puede ser la misma que la de aquel que es ribereño de un mar interior, el Mediterráneo - el Báltico por ejemplo, donde a veces desde la costa de un Estado se divisan sobre la línea del horizonte los perfiles de las costas de otro. Un dictado del buen sentido y de la lógica jurídica señala para el primero de esos Estados una opción a disfrutar de un mar territorial más vasto que el que pueda atribuirse al segundo. La flexibilidad en la variedad ha de ser, pues, la peculiar característica de los mares territoriales en la concepción contemporánea.

En cambio, la llegada del siglo $X X$ señala un vuelco en la historia social del mundo e infunde en el Derecho el estímulo de preocupaciones que antes no conoció. La explosión demográfica asoma como Il más grande, acaso, de los problemas de la humanidad, con su cortejo de previsibles déficits de subsistencias, de agudas crisis de escasez de la vivienda $y$ de inminentes perspectivas de desempleo por falta de medios de trabajo, con la agravante de que el progreso técnico disminuye la mano de obra. Como promisor alivio, los fecundos logros tecnológicos ofrecen cada día nuevos medios para incrementar la utilización de los recursos naturales en la atmósfera, en las entrañas de la tierra y en las profundidades del mar; pero, con desgraciada equivalencia, los desechos de la gran industria, los detritus de las ciudades $y$ los despojos de los naufragios emponzoñan el aire $y$ contaminan, las aguas marinas $y$ su preciosa fauna ictiológica.

Por último, las dos guerras mundiales con sus millones de vidas frustradas, su estéril secuela de ruinas $\vee$ sus vejámenes de la civilización, dejan una lección incuestionable: en adelante, el deber primordial de las naciones habrá de centrarse en preservar, defender $y$ promover al Hombre con todo lo que le es inherente; su dignidad de persona, sus fueros de ser pensante, sus funciones de elemento de una sociedad de convivencia organizada, su derecho a intervenir en la función pública, su vida necesitada de salud $y$ de subsistencias.

Consecuentemente, el Derecho Internacional ha debido cambiar también su centro de gravitación y de objetivos, el cual será en lo sucesivo no ya el Estado, sino el Hombre. El Estado ha asumido la carga de procurar para el Hombre la consecución de los fines temporales de su existencia $y$ de facilitarle el acceso a los recursos que ha menester.

Dentro de esta idea, el mar territorial abarca, como pertenencia del Estado en tanto que administrador de los fines del Hombre, todos los recursos naturales alli contenidos y utilizables o requeridos para el sostenimiento y desarrollo de la población humana del territorio ribereño; $\vee$ ello, en la longitud $y$ dimensiones que razonablemente iuzgue prudente el Estado asignar a esa zona marítima en función de las condiciones geográficas de sus costas $y$ del mayor o menor grado de necesidad de los recursos por parte de los pobladores. A un menor desarrollo del país, a un índice más pobre de calorías o de unidades proteínicas por habitante en las dosis alimenticia, corresponderá una mayor opción al acceso de los recursos y al área de soberanía maríti. ma. Quiere decir, pues, que si un Estado juzga suficiente para sus fines legítimos un ancho de 60 ó 100 millas, fijará en esa cifra la medida de su mar territorial.

En este sentido deben ser precisados los alcances de la que se ha llamado, demasiado genéricamente, "doctrina de las 200 millas". No es, como propalan sus adversarios, que se pretenda rodear todas las costas del mundo de un cinturón uniforme de esa dimensión, sino que las 200 millas indicarán el máximo de anchura a que puedan llegar los mares territoriales, muchos de los cuales en la práctica habrán de ser más reducidos, ya por razón de estre- 
chez en la conformación geográfica de los parajes, ya por la pobreza local de los recursos ictiológicos - mineros, ya por otros motivos. La misión de una Asamblea de Estados como la de Caracas no ha de llegar presumiblemente en estos casos sino a fijar los topes máximos de la línea exterior de los mares territoriales, pero siempre sobre la base antelada de los principios científicos y sociológicos en que reposa la nueva doctrina del Derecho Internacional.

Bajo otros aspectos, el espiritu de post-guerra ha hecho variar también en el Derecho Público la estructura constitucional de las naciones: el colonialismo ha desaparecido virtualmente; y las antiguas colonias, hoy pueblos independientes, tienen la facultad de ejercitar su derecho de libre determinación acerca de los problemas de la comunidad internacional sobre los cuales se pronunciaron dos siglos antes sus antiguas metrópolis. Obvio es admitir que en lo tocante - por ejemplo- al Derecho del Mar, los flamantes Estados no han de ratificar la moción de las tres millas que para los mares territoriales preconizaron en aquel entonces las potencias metropolitanas. Otro tanto ocurre en el aspecto tecnológico: la exploración de los recursos submarinos, que hasta hace pocos años no era factible más allá de los trescientos metros de profundidad, se realiza actualmente aún por debajo de los mil metros; y de ello emanan nuevas posibilidades económicas y jurídicas para el Estado ribereño, $v$ alteraciones en el régimen de la plataforma continental.

Pruebas irrecusables son todas éstas de cómo el mundo ha dado un vuelco y de cómo se han transformado radicalmente las bases de la sociabilidad $y$ del Derecho. Se verá claro ahora por qué dije al comienzo de este estudio que en lo que concierne al Derecho del Mar se precisa una tarea que no sea de transacciones y remiendos, sino de auténtica creación de un Derecho NUEVO, buscando, más que el precedente jurídico o un consenso general mínimo de opiniones, la sana evolución de la doctrina. En el devenir del perfeccionamiento humano, la evolución únicamente no alcanza a modificar ciertas nociones básicas o conceptos primarios $d \in \mid$ ser y del vivir que, como el bien y el mal, la justicia y la responsabilidad, son permanentes e intangibles en la conciencia humana por encima del tiempo $y$ de los vaivenes de la voluntad.

II

Inspirado en la convicción de que era indispen. sable -ante la ausencia de una iniciativa de los or- ganismos internacionales oficiales- afrontar de una vez por todas una renovación de ciertas pautas de Derecho, en lo tocante a nuestro propio mar, y partiendo de ciertos precedentes sentados por la actitud de otros Estados americanos (Estados Unidos por boca de su Presidente Truman, México, República Argentina y Chile), el Perú proclamó hace veintisiete años la soberanía y jurisdicción nacionales sobre su mar aledaño en una extensión de hasta doscientas millas marítimas frente a la costa, sin perjuicio de la libre navegación de naves de todas las naciones. Tal proclamación implicaba asignar a esa área la calidad de mar territorial, pues en el Derecho Internacional el atributo de la soberania -referido al Estado ribereño- corresponde exclusivamente a esta clasè de mar.

La asignación de una anchura de 200 millas al mar territorial peruano no fue hecha a humo de pajas o en forma antojadiza: se hizo con referencia a la Corriente de Humboldt, llamada también Corriente Peruana, que en buena parte del año alcanza esa misma anchura máxima. A lo largo de ese curso de agua vive $y$ fluye, como en su propio "habitat", una profusa variedad de especies ictiológicas, desde el cetáceo hasta la anchoveta, constituyendo un "complejo biológico" de admirable cohesión funcional $y$ de unidad indivisible, como lo demuestran las leyes naturales de la llamada "cadena nutritiva" (1), la proliferación de plancton a beneficio de los peces y el influjo de la erosión mineral de las costas en la fertilización planctónica. Esa Corriente, que discurre pegada a la costa peruana, no podría ser segmentada ni desarticulada en cuanto a su administración estatal mediante una artificiosa frontera imaginaria con el mar libre - porque ello mutilaría en su trabazón integral toda labor soberana de policía, preservación, aprovechamiento o defensa de la riqueza allí existente. El complejo biológico es un todo con su "habitat" que es la Corriente, como una unidad orgánica; y por ello ese todo no debe disgregarse.

Esta especialísima posición del Perú, respecto de la Corriente, poco menos que UNICA pues sólo coparticipan de ella el litoral Norte de Chile y las costas del Ecuador, otorga también a nuestro país un título jurídico especial y poco menos que exclusivo para reclamar como mar suyo el comprendido en el trayecto peruano de esa Corriente a todo el ancho de ésta, con todos los atributos de un mar territorial- pues mal podría el Estado vigilar, preser-

(1) En virtud de ella, unos peces devoran a otros más débiles como recurso normal alimenticio. 
var, promover, aprovechar $y$ defender los recursos naturales de ese trayecto si no goza de los derechos inherentes a la soberanía para imponer allí su autoridad.

Esta ampliación de los derechos de potestad soberana al área también ampliada de los mares terri. toriales, que preconiza el nuevo Derecho del Mar, no es, por lo demás, sino una consecuencia de las mayores responsabilidades que la moderna concepción sociológica $\vee$ humana del mar territoriał impone al Estado ribereño en cuanto a la custodia y uso de ese mar como fuente natural de recursos de" la economía nacional de su pueblo, y, por tanto, elemento esencial de consecución de los fines del Estado. No se trata ya únicamente como en el Derecho antiguo, de repeler a tiros de cañón la asechanza eventual de posibles agresores. Se trata de una tarea permanente y compleja de administración integral, que abarca la procuración de alimentos marinos, la explotación marina y submarina de recursos orgánicos e inorgánicos, la lucha contra la usurpación.de intrusos que pretendan burlar las prioridades nacionales $y$ contra la depredación de los bienes marítimos por propios o extraños, la prevención de las causas $y$ de los efectos de la contaminación ambiental y marina $y$, finalmente, la supervigilancia de las expediciones de investigación científica que, con tanta frecuencia, y con membretes inocentes, disimulan el propósito de arrancar secretos naturales, detectar informaciones in situ o estudiar con interesada perspectiva las posibilidades económicas o industriales de la zona explorada. Resultaría ingenuo sostener que este cúmulo de facultades y precaucio. nes pueda ser ejercido por una autoridad que carezca de la potestad soberana. No nos hagamos ilusiones ni admitamos disfraz de la verdad: en estos ca. sos, una soberanía a medias, una jurisdicción dosificada por gotas o extensiva a sólo ciertos campos de dominio, es tan sólo un peligro o una ficción.

La conclusión es clara: la admisión de un mar territorial ampliado razonablemente es la solución cuerda para los mares territoriales del mundo; sin que pueda decirse -ropetimos-que esa ampliación signifique invariablemente una faja uniforme de doscientas millas ni un recorte oneroso de la libertad de los mares, pues serán muchos los Estados que por su emplazamiento geográfico o por sus peculiares circunstancias de orden físico o social, señalarán una anchura menor.

Sin embargo, como este argumento referente al carácter oneroso de la medida se esgrime con notoria insistencia, cabe añadir que la noción de la liber- tad de los mares ha sufrido reveses y variantes en el avance de los tiempos: del antiguo concepto irrestricto de esa libertad, que alentaba la piratería, el contrabando o tráfico ilícito y la impunidad penal, sólo han quedado vigentes como elementos reglamentables la pesca pacífica, en alta mar, y la libertad de paso o comunicaciones; elementos de los cuales el primero nadie discute, y en cuanto al segundo, todos o casi todos los Estados lo reconocen. hoy igualmente aún dentro de sus "mares territoya sin traba alguna, ya bajo las formas de "paso inocente" que no es otra cosa que una libertad de tránsito condicionada al uso pacífico en territorio ajeno, conforme al principio universal de la "buena $\mathrm{fe}^{\prime \prime}$ que rige en el Derecho Internacional.

$\mathrm{Si}$, por acaso, existen potencias que no se resignan a ese simple "paso inocente" de sus naves mercantes o de guerra, submarinas o de superficie, por aguas territoriales de terceros en tiempos de paz, parece ser éste el momento de reconsiderar tal criterio y situarse dentro de la nueva realidad jurídica.

En tiempo de paz, el principio de "buena fe" es el único válido en Derecho de Gentes; $Y$ según ese principio, no tiene explicación alguna que las naves de guerra de un Estado incursionen en mares ajenos $\sin$ aviso $y \sin$ licnecia del soberano. Lo que allí existe no es una restricción del libre tránsitá de un lado, sino un intento de exceso de poder, del otro lado.

\section{III}

Frente a la solidez de la tendencia doctrinal hacia la ampliación de los mares territoriales y presumiblemente con el designio de enervarla, se ha dado en asumir cierta reticente actitud contra este calificativo que al mencionar la "territorialidad", enuncia un nexo sustancial con el territorio; $y$ es perceptible un movimiento dirigido a un cambio de la terminologia jurídica aceptada, sustituyendo la voz "territorial" por alguno de otros vocablos poco afortuna-. dos. Pero no es razonable ese propósito, ya que difícilmente podrá encontrarse una mejor expresión que la del adjetivo "territorial" para designar. un mar que por sus características propias - resumidas en el hecho de su dependencia plena de la soberanía local- se identifica e integra con el territorio mismo, en una sola unidad de derecho.

Entre las fórmulas escogidas figura una que concibe el mar ribereño de cada Estado como integrado por dos fracciones contiguas entre sí y paralelas ambas a la costa: la primera constituida por el mar 
nacional o territorial, pegada a tierra $y$ con un ancho de doce millas (según lo enunciado en Ginebra de 1958) sobre la cual el Estado ejerce su soberanía total; y la segunda llamada "mar patrimonial" (que algunos denominan también "mar económico"), lado a lado de la fracción anterior y comprendida entre la doce $y$ las doscientas millas, como un remedo de la ya ensayada "zona contigua". Esta segunda fracción entra en rigor en la antigua clasificación de "alta mar" pero con la taxativa de que allí el Estado ejercería una porción limitada de soberanía o, para decirlo con mayor propiedad, una forma de jurisdicción especial sólo para el aprovechamiento de los recursos ictiológicos mediante la pesca a beneficio de los habitantes locales y con prioridad sobre pescadores extranjeros.

Esta proyectada innovación, no sólo afecta desventajosamente la terminología legal, sino ofrece además serios reparos de carácter sustantivo. De un lado, reduce a doce millas la extensión del mar territorial, que resulta así tan desmedrada e insuficiente como lo era la de tres millas dos siglos atrás, si se tiene en cuenta que, según la concepción contem. poránea, ese mar constituye el depósito de los recursos naturales marítimos de la nación ribereña. De otro lado, la fórmula exhibe un nuevo esfuerzo de los Estados tradicionalmente pescadores para reducir en lo posible el área de los mares territoriales $y$ para llevar sus flotas a las costas de remotos paises ricos en fauna marina, cercenando con ello la legítima opción que estos últimos poseen de ejercitar la pesca en sus propias regiones geográficas.

Agréguense a la dicho; las dificultades y conflictos que este régimen híbrido del mar ribereño habrá de causar al Estado local para cumplir sus funciones de preservación de las aguas de tos riesgos de depreciación y contaminación $\mathrm{y}$ del espionaje pseudo cient ífico.

Fácil es comprender que esta llamada tesis del "mar patrimonial" no ha dejado de levantar objeciones a fin de contrarrestar sus deficiencias y peligros; y así, ha trascendido el dato de que en las conferencias preparatorias de la convocada en Caracas se ha enunciado una enmienda a la cual se llama "la variante dura del mar patrimonial" en el sentido de que el derecho del Estado ribereño debe abarcar no sólo una opción exclusiva al ejercicio de la pesca, sino la propiedad de los recursos naturales todos del suelo $y$ subsuelo marinos, todo ello con real soberanía; $\sin$ perjuicio de las licencias que el Estado podrá otorgar a Terceros sobre la exploración, explota. ción y otras actividades industriales en esa zona, que sería de libre navegación.

Una nueva faceta en los problemas referentes al. mar territorial vino a hacerse presente cuando hace pocos años fue presentada en Naciones Unidas, con el franco patrocinio de las grandes potencias, la llamada "Proposición de Malta": una tesis acerca de la utilización de los fondos marinos según la cual se declara que estos fondos de la alta mar y todos sus recursos y riquezas, a partir de la línea exterior de los mares territoriales donde termina la soberanía $V$ jurisdicción de los Estados ribereños, constituyen patrimonio común de la Humanidad y deben ser aprovechados en beneficio del Hombre para su subsisten. cia y desarrollo integral. Sabido es que "alta mar" o "mar libre", como bien de la comunidad internacio. nal, era en Derecho un dominio de todos y de nadie; pero en la práctica, se reducía ser un dominio inmóvil o pasivo $y$ en cierto modo estéril, como no fuese en su aspecto de instrumento de comunicaciones. Asociado hoy ese dominio al problema demográfico (plétora de población, aumento de necesidades, escasez de recursos), se quiere darle una finalidad de efectivo provecho humano. Desde este punto de vista, el proyecto no merece sino elogio.

Pero al ser él tramitado en Naciones Unidas, se incurrió en una extraña y deplorable omisión. Acaso el deslumbramiento del objetivo humanitario perturbó en ciertos Estados. Miembros la visión de un hecho que debía ser considerado preliminarmente, antes de entrar en el análisis de la iniciativa maltesa. Hasta aquel momento el Derecho Internacional no había logrado definir la posición del lindero exterior de los mares territoriales ni la extensión de sus dimensiones hacia "alta mar"; y a la elucidación de este "suspenso" se hallaba inscrita entre los asuntos pendientes en el "Orden del Día" de la Organiza. ción. Lo natural habría sido, pues, que al dar paso a la propuesta de los "Fondos Marinos" y al instituir la Comisión que habia de estudiarla, las Naciones Unidas dejaran constancia expresa de que ello no implicaba en favor del flamante enunciado ninguna prioridad de trato en el "Orden del Dia"; $y$, antes bien, que esa prioridad correspondía a los problemas sobre el régimen de los mares territoriales; toda vez que mientras no fuese conocido y sancionado el límite externo de estos últimos, no podía en manera alguna ser determinada el área ni los límites de los "Fondos Marinos". Pero no se hizo asi, y los "Fondos" quedaron como tema preferente. Por tanto, es preciso que ahora, al iniciarse la Conferencia de Caracas, las Delegaciones territoriales 
exijan de la Mesa Directiva que el yerro se rectifique, en el explicable interés de imponer en los de bates el método y la equidad que el Derecho y la lógica reclaman.

Anticipándome a la discusión-dentro de la Conferencia- de lo que constituye la enjundia de la propuesta sobre "Fondos Marinos", quiero hacer una apostilla que puede -en su momento- servir de saludable prevención contra un espejismo capaz de crear inmotivados prejuicios contra cualquier acuerdo general de ampliación de los mares territoriales. De primera intención, es fascinante el argumento de que una agrupación de todos los Estados del mundo, creada para hacer de los recursos de los "Fondos Marinos" una reserva comunitaria universal, ofrecería una perspectiva más humanizante y generosa que la que pudieran presentar muchos países in dividualmente dedicados a explotar por sectores nacionales la fracción de esos recursos comprendida en la zona de ampliación de cada mar territorial. Pero examinado el caso en su fria realidad objetiva se comprueba que las cuatro quintas partes -o sea el 80 por ciento de los Estados del mundo actual tienen ribera maritima, correspondiendo sólo el quinto restante- o sea el 20 por ciento a los Estados mediterráneos (que son alrededor de 30 sobre 150); de modo que aquella copiosa mayoría del 80 por cien to de Estados hoy provistos o dispuestos a proveer se de mares territoriales amplios, serian ya beneficiarios efectivos o potenciales de los recursos inmersos $y$ profundos de ese litoral y estarían en aptitud de explotarlos y administrarlos por sí mismos en todo el ancho de sus costas, sin la necesidad de la ingerencia de terceros Estados u Organismos, con la ventaja adicional de evitar el gigantesco y costoso aparato de un Cuerpo de regencia ejecutiva mundial manejado por manos burocráticas.

En nuestra época, el poder de las finanzas internacionales y las facilidades del crédito capacitan a cualquier Estado, aún a los no desarrollados sufi. cientemente, para flotar grandes empresas y utilizar los más altos exponentes de la tecnología. Por cierto que este régimen uninacional abarcaría solamente las fajas de aguas ribereñas constitutivas de los mares territoriales no excedentes del máximum permisible de 200 millas: en lo que concierne a los "Fondos Marinos" propiamente dichos, o sea el núcleo central de cada uno de los océanos, excluida la faja circundante sometida a la territorialidad, se podría iniciar alli el régimen de internacionalización previsto en la propuesta ecuménica de Malta con prudente graduación, dando la opción sin distingos 10 al aprovechamiento de los recursos por todos los Estados del orbe; $y$ entonces cabría también deter. minar si las cuotas de participación en los beneficios que se obtuvieran de ese núcleo industrializado habrán de ser proporcionales a la longitud de las riberas de cada Estado marítimo o si, en aras de la justicia social, serán inversamente proporcionales al grado de desarrollo integral de cada Estado o a su grado de solvencia financiera, es decir, que a menor desarrollo, mayor proporción de cuota adjudicable.

Finalmente, en lo tocante a los Estados mediterráneos, cabría una doble opción: va la celebración de pactos convencionales de Estado a Estado sobre otorgamiento de salidas territoriales al mar, creación de puertos o aeropuertos libres $u$ otro género de liberalidades compensatorias, en los casos en que antecedentes históricos especiales justificaran tales fórmulas; o ya la asignación por parte de la Comunidad Internacional, dueña de los Fondos Marinos, de una cuota periódica razonable proveniente de los beneficios que rindan esos Fondos, en vía de indemnización por el enclaustramiento territorial; todo ello sin perjuicio de una legislación internacional que determine las obligaciones de vecindad que en cuanto a tránsito. $y$ aduanas deban reconocer los Estados maritimos contiguos en favor de los Estados en clausura geográfica.

Esta visualización panorámica de la tesis sobre "Fondos Marinos" muestra que la fórmula de internacionalización comunitaria sometida a Naciones Unidas no es la única posible; y que cabe una coexistencia de sistemas que, sin excluir la comunidad para los núcleos oceánicos, deje a los Estados marítimos en aptitud de mantener bajo su dominio y de explotar por sí mismos los fondos de sus mares territoriales, ampliados a juicio de los interesados hasta una distancia de no más de 200 millas de la costa.

Por eso, al resolver este problema, procuremos descartar todo espejismo de grandiosos proyectos que lindan en lo supranacional y puedan resultar por el momento prematuros o inasibles; $y$ atengámonos a la realidad para mejorarla y superarla juiciosamente.

Es comprensible que el afán de las evoluciones aceleradas pueda suscitar el deseo de introducir en la estructura de Naciones Unidas un ensayo de la empresa única internacionalizada en forma poco menos que supranacional, para de este modo, comenzando por la vía del fenómeno económico, llevar a los hombres al desideratum de un gobierno mundial único. 
Pero en tanto que no arraigue en las concien- ds la convencida certidumbre de que un Poder Su"yemo internacional no habrá de inspirarse en otros incipios que los de la fraternidad, la igualdad, la r:onestidad y la justicia (en vez de hacerlo en ciertas prácticas que actualmente predominan de prepotencia hegemónica, de egoísmo inhumano de los intereses, de diplomacia secreta que estrangula la formación de la opinión pública sobre el destino futuro del mundo, y de escarceos bélicos de ensayo traducidos en oscuras guerras locales detrás de las cuales parecerían alentar designios de hegemonía política o económica) no es probable que un consenso mundial de Estados se avenga a reemplazar por un supranacionalismo incierto, verosímilmente proclive a la dictadura, el actual régimen de las nacionalidades defendido por el relativo resguardo de las soberanías estatales.

\section{IV}

En los últimos años y como proceso preparatorio para la definitiva conferencia sobre Derecho del Mar, se han efectuado repetidas reuniones preliminares, unas entre grupos de Estados Iatinoamericanos o del Tercer Mundo $y$, otras, en los Estados Unidos bajo la égida de Naciones Unidas; habiendo aportado igualmente su colaboración el Comité Interamericano de Juristas de Río de Janeiro.

Aunque esas reuniones se han señalado por la parquedad de informaciones acerca de su contenido, ha podido saberse que en lo que toca al fondo de los problemas las labores no consistieron propiamente en la defensa argumental de la doctrina sostenida por los diferentes Estados sobre cada materia en el campo del Derecho, sino más bien en el empeño de escudriñar y reunir los "puntos de coincidencia" que en lo tocante a la nueva legislación del mar pudieran servir de base a una plataforma mínima común, a fin de que en el momento de las formulaciones contractuales fuese factible llegar a la suscripción de los llamados "tratados-marco", dentro de los cuales cupiera un consenso general o de principio sobre los temas básicos, aunque también variantes de extensión o de matices dentro del marco de las estipulaciones.

Con el natural respeto, me permito disentir de esta metodología porque creo que ella no garantizả el verdadero avance del Derecho en cuanto disciplina científica doctrinal. El sistema del "consenso mínimo" o del "mínimum de coincidencias" no construye ni crea Derecho: cuando más, registra o recoge lo que en un determinado momento constitu. ye la política jurídica de cada Estado; y todos sabe- mos que las realidades jurídicas exhiben la "política nacional", mas no siempre la puridad del pensamiento doctrinario $y$ justiciero en cada tema o materia. Lo que todo el mundo desea en la próxima Conferencia es que se alcance la forja de un nuevo $y$ auténtico Derecho del Mar, que prescribe lo que "debe ser" y no simplemente lo que "es"; que tra sunte las exigencias actuales de la justicia y las nuevas tendencias sociales donde bullen esas exigencias $y$ en ningún caso las tendencias particularistas de cada Estado. En este sentido, lo más útil habría sido tal vez acordar que en las reuniones preliminares cada Delegación hiciera conocer abiertamente la posición de principio $y$ de legislación que su país hubiese adoptado sobre cada uno de los temas básicos, dígase mar territorial, mar patrimonial, plataforma submarina o fondos marinos oceánicos, con la consiguiente alegación de argumentos y motivos de hecho $y$ de derecho, a fin de que su fuerza persuasiva allegase nuevos prosélitos a la posición enunciada. De este modo se habría contado en la etapa actual con un caudal más rico de enunciados doctrinales $y$ con un bagaje más depurado $y$ completo de puntos armonizados en los debates internos, en vez del vago y confuso cúmulo de conjeturas con que ingresa la Conferencia a su etapa de deliberaciones.

En otro aspecto han dejado también deficiencias las reuniones preparatorias; $y$ es en el de la publicidad. Ha escaseado la información oficial sobre ellas $y$, consecuentemente, la información de prensa. Se ha hecho en buena cuenta trabajo de gabinete, pero cuya entraña no ha podido ser aireada por el comentario periodístico ni por la crítica oportuna de la opinión culta. $Y$ así, el advenimiento de la Conferencia viene a sorprender a las gentes en una actitud de carencia de luces sobre lo que va a ser realmente este certamen. Menos mal que en los recientes días la diligencia de los corresponsales de agencias noticiosas se ha esforzado desde Caracas en transmitir detalles de último momento sobre los principales problemas de sustancia $y$ de procedimien. to que inquietan a los dirigentes de la desbordante Asamblea.

Así asoma la Conferencia de Caracas como la convocatoria más numerosa y una de las más importantes de los últimos tiempos, para tratar de un tema de expectativa mundial. No cabe sino hacer votos por su éxito en bien de la. Humanidad; pero sin olvidar que, para verlo conseguido, será preciso que las Delegaciones de los Estados lleven la decisión de HACER DERECHO; de acuñar un verdadero Derecho del Mar $y$ no una Política del Mar.

Lima, junio de 1974. 